\title{
Chemiluminescence Parameter for the Degradation of Polyolefins
}

\author{
Hayato KiHARA and Satoru Hosoda \\ Sumitomo Chemical Co., Ltd., Chiba Research Laboratory, \\ Anesakikaigan 5-1, Ichihara, Chiba 299-01, Japan
}

(Received December 21, 1989)

\begin{abstract}
The chemiluminescence time-courses of various polymer materials under heating in air or inert gas were observed and simulated on the basis of kinetic analysis. Chemiluminescence parameters, such as peak-top intensity, integrated intensity during measurement, steady state intensity, and chemiluminescence decay rate, were found to strongly correlate with the stability of polymer materials, judging from correspondence with the results of durability tests on the same materials. The relationship between the chemiluminescence and the structural characteristics of the polymer was also investigated.

KEY WORDS Chemiluminescence Parameter / Degradation / Durability / Heating / Kinetic Analysis / Polypropyrene / Polyethylene /
\end{abstract}

Generally, the degradation of polymer materials is caused by various factors such as heat, UV light, irradiation, ozone, mechanical stress, microbes, and promoted by oxygen, humidity, strain, etc. The durability of polymers was evaluated by tests under thermal aging, out-door exposure, UV irradiation, repeated stress and so on.

These tests commonly need much time, e.g., $100-1000$ hours for heat resistance test and a few month for out-door exposure test. On the other hand, chemiluminescence (CL) measurement is sensitive to catch the very first stage of oxidation of polymers and does not require so long time to obtain the information. Since the preceeding studies of CL in polymers ${ }^{1,2}$ appeared, many applications for various polymers have been reported. ${ }^{3-17}$ However, very few papers can be seen in which the results of CL measurement are discussed in connection with the results of actual durability tests. From this point of view, in this work, we investigated the CL phenomena induced by heat and propose CL parameters to evaluate the stability of polymer materials.

\section{EXPERIMENTAL}

\section{Materials}

Polypropylene (PP; Sumitomo Noblen, $M_{w}=2.0 \times 10^{5}$ ) and polyethylene (PE; Sumikathene-L, $M_{w}=1.3 \times 10^{5}$ ) used in this study are commercial products of Sumitomo Chemical Co., Ltd. They were purified, as occasion demands, by reprecipitation using xylene/ methanol mixture. The additives such as antioxidants, were mixed into PP in molten state by using a Brabender Plasticorder. Sample specimens were hot-press molded to a sheet of $3 \times 3 \mathrm{~cm}^{2}$ and $0.5-1 \mathrm{~mm}$ in thickness. Samples having different thermal history were obtained by heating at $200^{\circ} \mathrm{C}$ in air during different period.

\section{Measurement}

CL was measured with a single photon counting method using a Chemiluminescence Analyzer OX-7-TC (Tohoku Electronic Industry Co., Ltd.) equipped with a micro computer. Sample temperature was controlled with a Temperature Processor Controller TLD-47 (Tohoku Electronic Industry Co., 
Ltd.). Argon gas or air was selected as the atmosphere in the sample cell according to the kind of measurement. The CL intensity was measured as a function of time. The gate times for the measurement were 1,10 , and $30 \mathrm{~s}$, and normarized as cps. The spin-spin relaxation time $\left(T_{2}\right)$ was measured using a pulsed NMR spectrometer PC-120 (Bruker Co., Ltd.), equipped with a degital memory and micro computer. The free induction decay (FID) curves of PE were measured by the solid echo method and resolved into several components by the least square method.

\section{RESULTS AND DISCUSSION}

\section{Kinetic Approach to Polymer Degradation}

A simple scheme of oxidation process for polymer sample is shown in Figure 1. Radical species $(R \cdot)$ produced by main chain scission or proton elimination which are caused by the action of heat, UV light, and mechanical stress partly react with $\mathrm{O}_{2}$ and form peroxy radical (ROO•). The activation energy of the ROO. formation reaction was estimated to be nearly equal to zero by Stivara. ${ }^{18}$ From studies on the oxidation of hydrocarbons, ${ }^{13}$ only the exothermic biomolecular reaction of ROO- is known to be able to excite a product ketone up to its first triplet state (RO*). Visible light is emitted as it returns to its ground state. According to Stivara, ${ }^{18}$ the activation energy of the ROO - biomolecular reaction $\left(\Delta E_{\mathrm{b}}\right)$ was estimated to be ca. $12 \mathrm{~kJ} \mathrm{~mol}^{-1}$, while the reaction between $\mathrm{ROO} \cdot$ and $\mathrm{R}$ has a larger activation energy of $c a .29 \mathrm{~kJ} \mathrm{~mol}^{-1}$. This suggests that contribution of the latter reaction can be neglected. Then, the intensity of light emitted, $I_{\mathrm{CL}}$, will be proportional to the rate of the biomolecular reaction and overall efficiency, $f$ (apparatus constants, yields of formation and emission of excited state),

$$
I_{\mathrm{CL}}=f \cdot k_{\mathrm{b}}[\mathrm{ROO} \cdot]^{2}
$$

where $k_{\mathrm{b}}$ is the rate constant of biomolecular reaction of $\mathrm{ROO} \cdot$. In the absence of an inhibitor, the next equation is valid,

$$
\mathrm{d}[\mathrm{ROO} \cdot] / \mathrm{d} t=\mathrm{R}_{\mathrm{i}}-k_{\mathrm{b}} \cdot[\mathrm{ROO} \cdot]^{2}
$$

where $R_{\mathrm{i}}$ is the rate of generation of ROO-, including the rates of generation of $R \cdot$ by heat, return from $R \cdot$ to $R$, and disappearance by recombination of $R \cdot$.

i) CL under Heating in Inert Gas

In the case of heating in inert gas, $R_{\mathrm{i}}$ is estimated to be zero. The temperature of the sample was increased at a rate of $20^{\circ} \mathrm{Cmin}^{-1}$ from room temperature, and kept at $90^{\circ} \mathrm{C}$. Then, we simulated the CL time-course using eq 1 and 2 . In the simulation, it was assumed

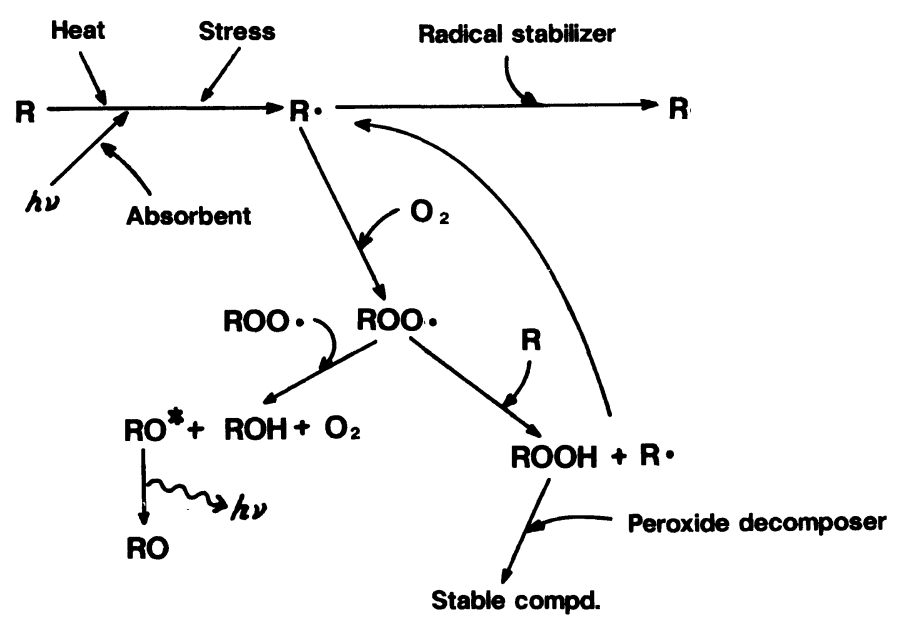

Figure 1. Simple scheme of oxidation and luminescence process for polymers. 

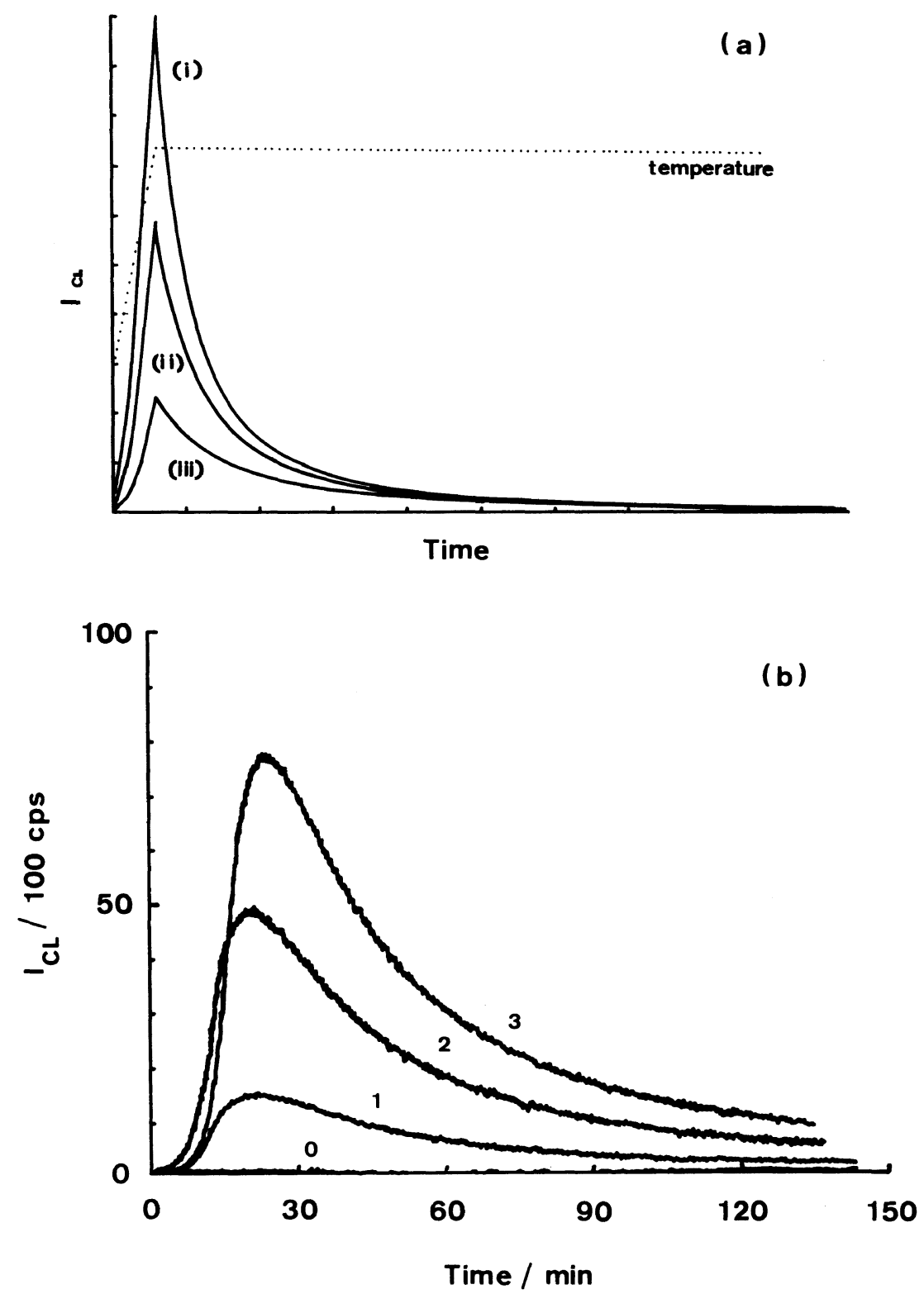

Figure 2. (a) Chemiluminescence time-course simulated by eq 1 and 2 in the text under oxygen free condition. $R_{\mathrm{i}}=0$, (i) $C_{0}=1.0$, (ii) $C_{0}=0.7$, and (iii) $C_{0}=0.4$. Dotted line shows temperature. (b) Experimental chemiluminescence time-course of polyethylene having a different thermal history, measured at $90^{\circ} \mathrm{C}$ in argon gas. Samples were heated at $200^{\circ} \mathrm{C}$ in air during different period. Numerals denote heating period in hours.

that $k_{\mathrm{b}}$ was propotional to $\exp \left(-\Delta E_{\mathrm{b}} / k T\right)$, are caused by temperature change. The where $T$ is the absolute temperature and $k$ is the Boltzmann factor. The rise and decay of the simulation curves, shown in Figure 2(a), peak-top intensity and integrated intensity (area) of the CL time-course increase with increasing $C_{0}$, which is the initial concentration 
of ROO and corresponds to the history of oxidation of the samples. Figure 2(b) shows the experimental $\mathrm{CL}$ time-courses of $\mathrm{PE}$ samples having different thermal histories, which were observed under heating in argon gas. The peak-top and area of the CL time-course of the samples obviously correspond to the thermal treatment period. This is in good agreement with the simulation described above. It is considered that the peak-top or area from this CL measurement can be used to indicate the oxidation history
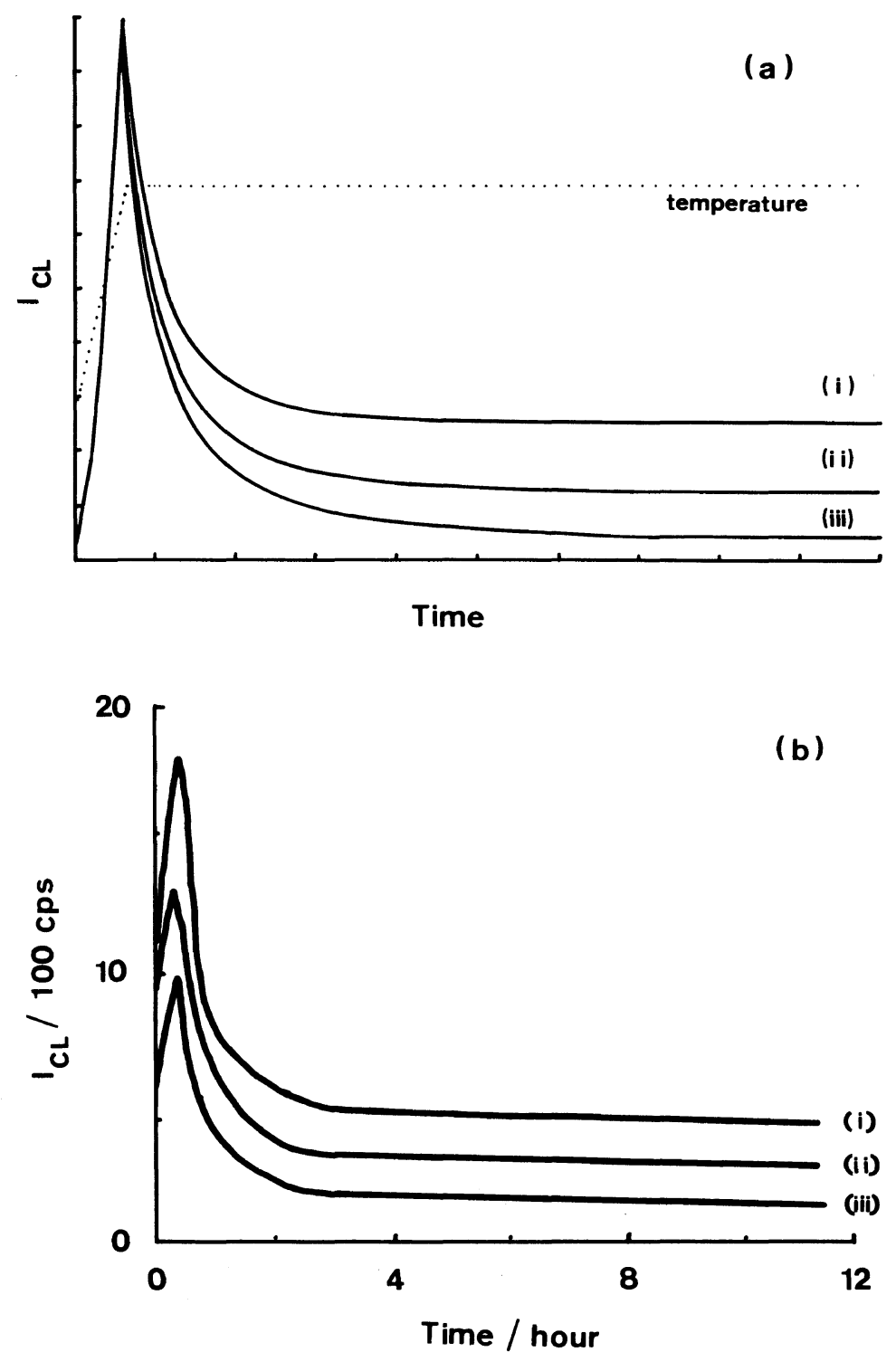

Figure 3. (a) Chemiluminescence time-course simulated by eq 1 and 2 in the text under oxidation condition in which $R_{\mathrm{i}}$ are (i) 0.03 , (ii) 0.015 , and (iii) 0.005 , respectively. Dotted line shows temperature. (b) Observed chemiluminescence time-course of stabilized polypropylene measured at $150^{\circ} \mathrm{C}$ in air. Concentrations of the hindered phenols in polypropylene are: (i) $\mathrm{PH}-1,250 \mathrm{ppm}$, (ii) $\mathrm{PH}-1,1000 \mathrm{ppm}$, and (iii) $\mathrm{PH}-2,1000 \mathrm{ppm}$. 
of polymer materials.

ii) CL under Heating in Air $\left(\mathrm{O}_{2}\right)$

Corresponding to the case of heating at a rate of $20^{\circ} \mathrm{C} \mathrm{min}^{-1}$ by $150^{\circ} \mathrm{C}$ in air $\left(\mathrm{O}_{2}\right)$, the CL time-course was simulated using eq 2 , where $C_{0}$ is constant, $R_{\mathrm{i}}$ is proportional to $\exp \left(-\Delta E_{\mathrm{i}} / k T\right)$, and $k_{\mathrm{b}}$ is to $\exp \left(-\Delta E_{\mathrm{b}} / k T\right)$. $\Delta E_{\mathrm{i}}$, which is the activation energy of the generation of $\mathrm{ROO} \cdot$, may be nearly equal to $\Delta E_{\mathrm{b}}$. When the temperature of the sample and oxygen concentration were kept constant, it was found from the simulation that the $\mathrm{CL}$ intensity converged to some difinite value during the time-course. In this steady state condition, $\mathrm{d}\left[\mathrm{ROO}^{\prime}\right] / \mathrm{d} t$ in eq 2 is zero, and CL intensity in this condition $\left(I_{\mathrm{s}}\right)$ can be expressed as follows.

$$
I_{\mathrm{s}}=f \cdot k_{\mathrm{b}}[\mathrm{ROO} \cdot]^{2}=f R_{\mathrm{i}}
$$

Equation 3 shows that $I_{\mathrm{s}}$ is proportional to the rate of generation of $\mathrm{ROO} \cdot\left(R_{\mathrm{i}}\right)$. In Figure 3(a), it is clear that $I_{\mathrm{s}}$ increases with increasing $R_{\mathrm{i}}$. Thus, it is possible from $I_{\mathrm{s}}$ to evaluate the ease of oxidation of polymers and the ability of inhibitors as radical captor. Figure 3(b) show

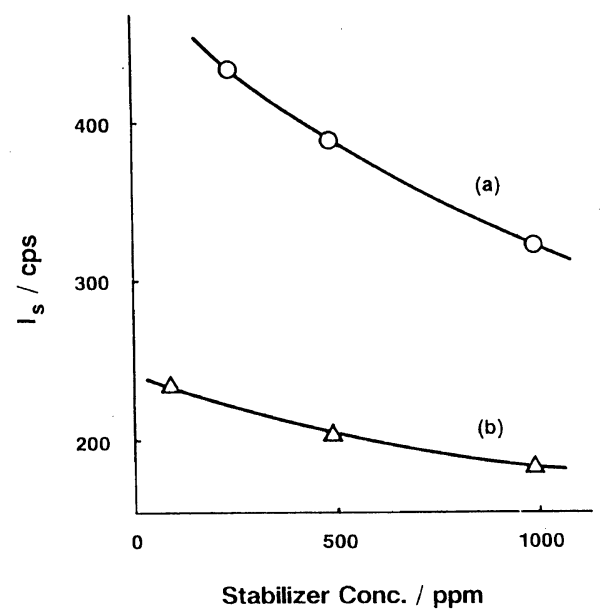

Figure 4. Stabilizer concentration dependence of steady state chemiluminescence intensity $\left(I_{\mathrm{s}}\right)$ for polypropylene at $150^{\circ} \mathrm{C}$ in air. (a), $\mathrm{PH}-1$; (b), $\mathrm{PH}-2$. the observed CL time-courses of the stabilized PP sheets which contain hindered phenols. The CL intensity gradually came down to a constant value after passing through a maximum value at the initial stage. Since these CL decay curves were not influenced by the concentration of the hindered phenols, the hindered phenols do not seem to quench the excited triplet state of carbonyls. Thus, this constant value after about 4 hours was taken as $I_{s}$. Figure 4 shows the dependence of $I_{\mathrm{s}}$ on the concentrations of the hindered phenols. $I_{\mathrm{s}}$ decreased with increasing concentration of the hindered phenols, and the hindered phenol $\mathrm{PH}-2^{\dagger}$ was found to have stronger ability to catch radicals in PP than $\mathrm{PH}-1^{\dagger}$. A reciprocal of Gear-Oven life ${ }^{19}$ of the same samples in air, which is one of the important parameters of durability, was found to have good linearity

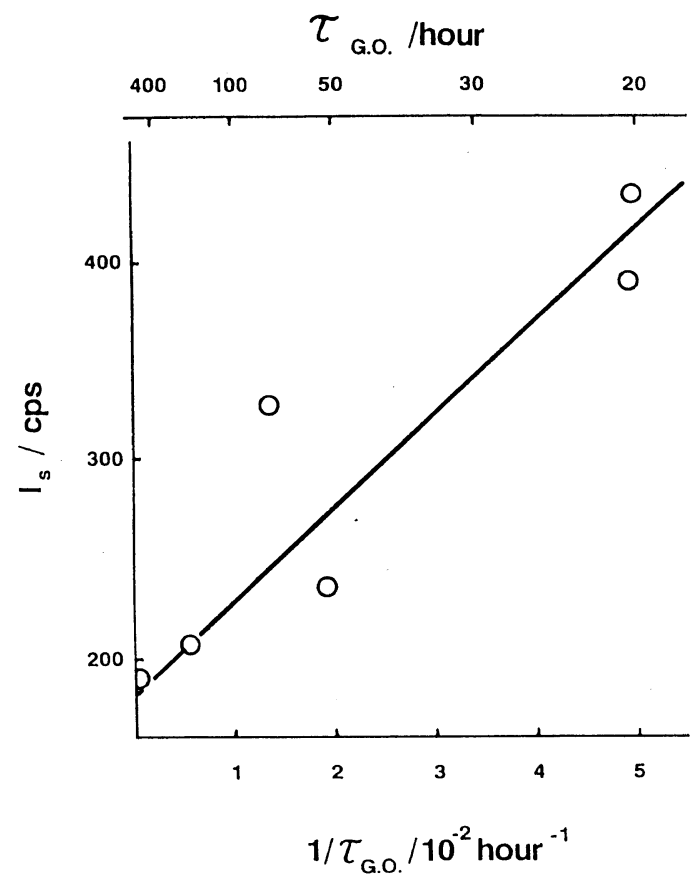

Figure 5. Relationship between reciprocal Gear-Oven life and steady state chemiluminescence intensity $\left(I_{\mathrm{s}}\right)$ of polypropylene at $150^{\circ} \mathrm{C}$ in air.

${ }^{\dagger}$ PH-1, n-octadecyl-3-(4'-hydroxy-3',5'-di-t-butylphenolpropionate); PH-2, tetrakis-[methylene-3-(3',5'-di-t-butyl$4^{\prime}$-hydroxy-phenylpropionate)]methane 
Table I. Steady state chemiluminescence intensity of polypropylene sheets containing various phenols

\begin{tabular}{|c|c|c|c|}
\hline \multirow{2}{*}{ Specimens } & \multirow{2}{*}{ Stabilizer $^{a}$} & \multirow{2}{*}{$\frac{\text { G.O. life }}{\mathrm{h}}$} & \multirow{2}{*}{$\frac{I_{\mathrm{s}}}{\text { Count } / 30 \mathrm{~s}}$} \\
\hline & & & \\
\hline 1 & $\mathbf{a}$ & 530 & $3.8 \times 10^{3}$ \\
\hline 2 & b & 1010 & $1.8 \times 10^{3}$ \\
\hline 3 & c & 1320 & $1.7 \times 10^{3}$ \\
\hline 4 & $\mathrm{~d}$ & 2130 & $1.4 \times 10^{3}$ \\
\hline
\end{tabular}

a a, 3,4-dimethylphenol; b, 4-methyl-2,6-di-tert-butylphenol; c, 2-tert-butyl-4-methylphenol; d, 2,3,6trimethylphenol.

Table II. Chemiluminescence decay rate and $T_{2}$ of polyethylene differing in thermal history

\begin{tabular}{ccccc}
\hline \multirow{2}{*}{$\begin{array}{c}\text { Heating } \\
\text { period }\end{array}$} & & \multicolumn{2}{c}{$\begin{array}{c}\text { CL decay } \\
\text { rate }\end{array}$} & \multicolumn{2}{c}{$T_{2} / \mu \mathrm{s}$} \\
\cline { 1 - 2 } \cline { 5 - 5 } $\mathrm{h}$ & $\mathrm{cps}^{-1 / 2} \mathrm{~s}^{-1}$ & & Crystalline & Amorphous \\
\hline 0 & $2.1 \times 10^{-3}$ & 13 & 53 \\
1 & $1.5 \times 10^{-3}$ & 13 & 46 \\
2 & $1.0 \times 10^{-3}$ & 12 & 41 \\
3 & $0.8 \times 10^{-3}$ & 12 & 41 \\
\hline
\end{tabular}

with $I_{\mathrm{s}}$ as shown in Figure 5. This indicates that the CL intensity at the steady state which is measured in air under heating corresponds to the rate of oxidative degradation. This is in good agreement with the simulation by eq 3 . Table I shows $I_{\mathrm{s}}$ and Gear-Oven life for PP sheets containing various phenols.

The results indicate that 2,4,6-trimethylphenol is the most effective among the phenols shown in Table II to stabilize PP. Thus, CL measurement, especially $I_{\mathrm{s}}$ measurement, which takes only a few hours to obtain information on polymer durability, is more favorable to evaluate the ability of additives than a time consuming test such as the Gear-Oven life test which takes several hundred hours or more.

iii) Chemiluminescence Decay (non static second order kinetic analysis)

If $R_{\mathrm{i}}$ is zero, the differential eq 2 gives the following equation,

$$
1 /[\mathrm{ROO} \cdot]=-k_{\mathrm{b}} \cdot t+1 / \mathrm{C}_{0}
$$

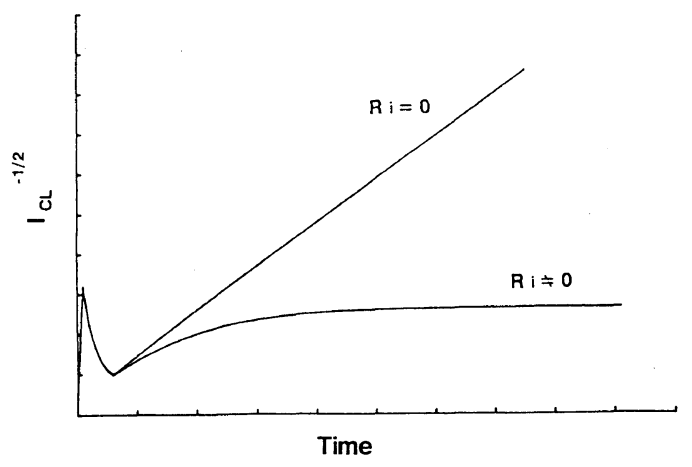

Figure 6. Simulated time-courses of the reciprocal of the square root of chemiluminescence intensity. $R_{\mathrm{i}}=0$ and $R_{\mathrm{i}} \neq 0$ corresspond to conditions under inert gas and under air $\left(\mathrm{O}_{2}\right)$, respectively.

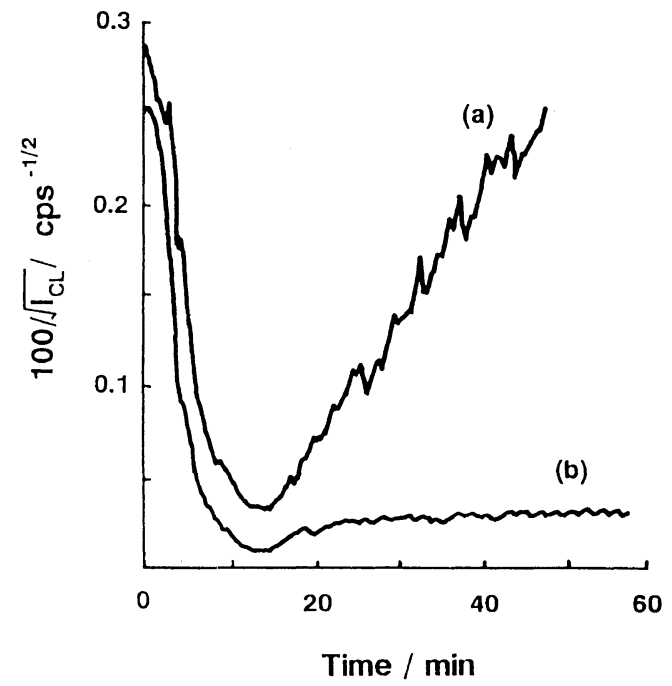

Figure 7. $1 / \sqrt{I_{\mathrm{CL}}}$ vs. time plots of polypropylene measured at $150^{\circ} \mathrm{C}$ : (a), in argon gas; (b), in air.

where $C_{0}$ is the initial concentration of ROO. Substituting eq 4 in eq 1 gives the following expression.

$$
1 / \sqrt{I_{\mathrm{CL}}}=\sqrt{k_{\mathrm{b}} / f} \cdot t+1 /\left(\sqrt{f \cdot k_{\mathrm{b}}} \cdot C_{0}\right)
$$

This equation reveales that the reciprocal of the square root of the CL intensity is propotional to time $(t)$.

Figure 6 shows the $1 / \sqrt{I_{\mathrm{CL}}}$ vs. $t$ plots simulated by use of eq. 1 and 2 . Good linearity is obtained between $1 / \sqrt{I_{\mathrm{CL}}}$ and $t$ when $R_{\mathrm{i}}$ is 
zero, while $1 / \sqrt{I_{\mathrm{CL}}}$ value saturates with increasing time when $R_{\mathrm{i}}$ is not zero. We confirmed this by measuring the CL of PP sheets heated at $150^{\circ} \mathrm{C}$ in air and in argon gas, which correspond to the cases of $R_{\mathrm{i}} \neq 0$ and of $R_{\mathrm{i}}=0$, respectively. These $1 / \sqrt{I_{\mathrm{CL}}} v s$. $t$ plots for $\mathrm{PP}$, which seem to be good agreement with simulation results, are shown in Figure 7. From

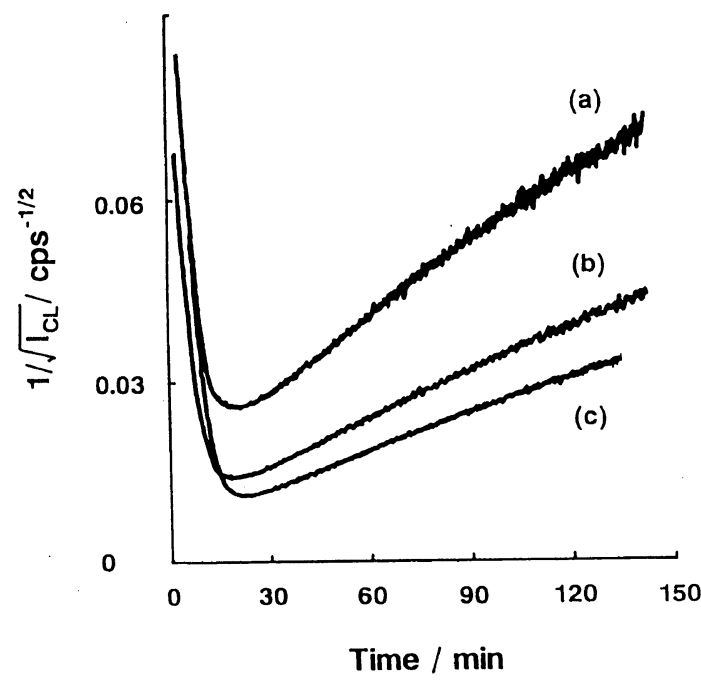

Figure 8. $1 / \sqrt{I_{\mathrm{CL}}}$ vs. time replots of polyethylene having a different thermal history in Figure 2(b) measured at $150^{\circ} \mathrm{C}$ in argon gas. Heating period: (a), $1 \mathrm{~h}$; (b), $2 \mathrm{~h}$; (c), $3 \mathrm{~h}$. eq. 5 the slope in Figure 7 is considered to correspond to the square root of the bimolecular reaction rate of $\mathrm{ROO} \cdot$. We may name this slope the CL decay rate in this paper. We replotted the results shown in Figure 2(b) into Figure 8, which shows that the CL decay rate of $P E$ sheet decreases with the heating period. It may be supposed that the molecular

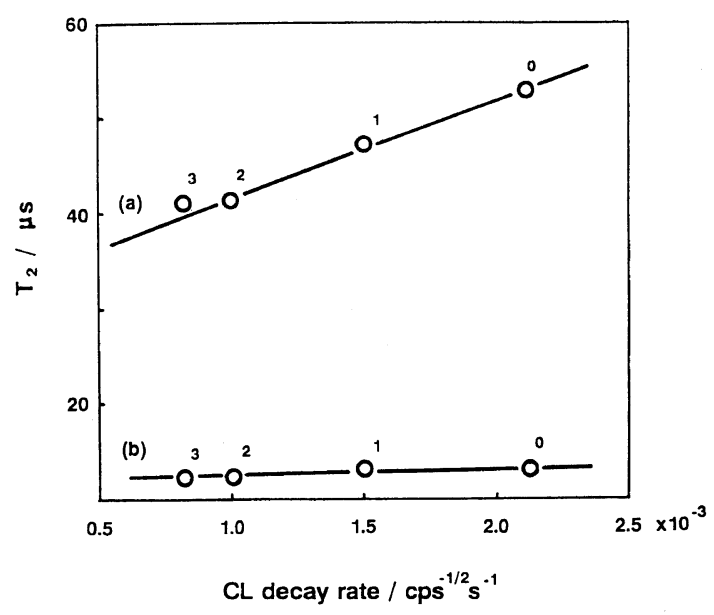

Figure 9. Relationship between chemiluminescence decay rate and $T_{2}$ of polyethylene having a different thermal history. Refer text and Figure 2(b). (a), amorphous phase; (b), crystalline phase. Numerals denote heating period in hours.
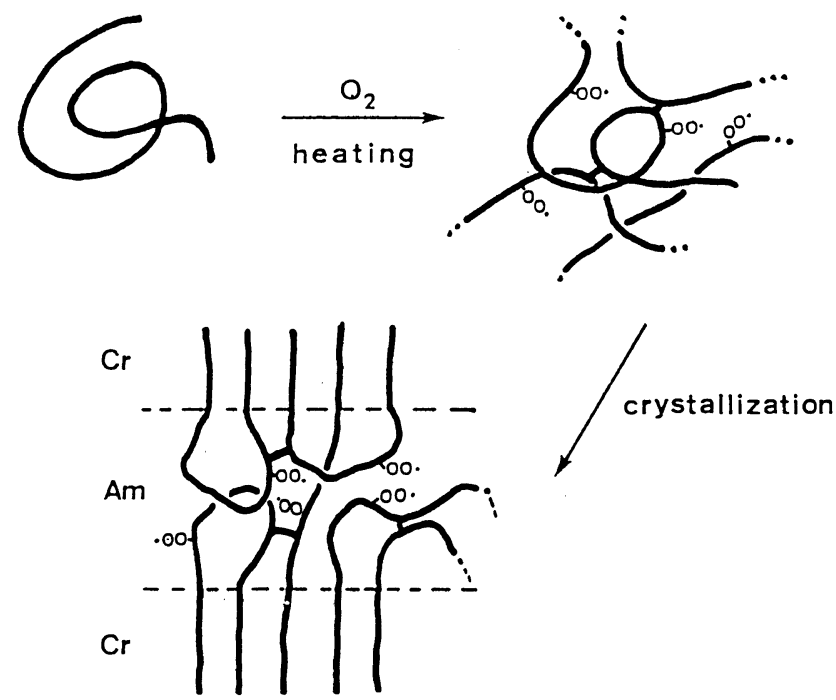

Figure 10. Structure change model of polyethylene when heated in air and recrystallized. 
mobility of PE chain decreases with aging since the biomolecular reaction rate of ROO. decreased with crosslinking of molecules. To make sure of this assumption, measurement of ${ }^{1} \mathrm{H}$ spin-spin relaxation time $\left(T_{2}\right)$ of $\mathrm{PE}$ sheets was carried out by a pulsed NMR spectroscopy at room temperature. The free induction decay (FID) obtained could be separated into this components. The short $T_{2}$ component is assigned to the crystalline phase and the long $T_{2}$ component to the disordered phase (amorphous phase) in the solid state of PE. The relationship between these $T_{2}$ values and CL decay rates is plotted in Figure 9. $T_{2}$ of the crystalline phase in PE was not altered by aging, while $T_{2}$ of the amorphous phase decreased with aging, suggesting that the mobility of amorphous molecular chains decreases. Changes in $T_{2}$ in the amorphous phase are in good agreement with the CL decay rate as shown in Table II. Since it is considered that both oxidation and crosslinking, generated at a molten state of PE, are condensed into the amorphous phase with crystallization, $T_{2}$ in the amorphous phase might correspond to the CL decay rate (Figure 10).

These experimental and theoretical results suggest that measurement of the CL decay rate in inert gas is useful to examine the degree of aging of polymer materials which age mainly by crosslinking.

\section{NOMENCLATURE}

$$
\begin{aligned}
& I_{\mathrm{CL}}=\text { chemiluminescence intensity }[\mathrm{cps}] \\
& {[\mathrm{ROO} \cdot]=\text { peroxy radical concentration }} \\
& R_{\mathrm{i}} \quad=\text { rate of generation of ROO } \\
& {\left[\mathrm{moll}^{-1}\right]} \\
& {\left[\mathrm{moll}^{-1} \mathrm{~s}^{-1}\right]} \\
& k_{\mathrm{b}} \quad=\text { Rate constant of bimolecular } \\
& \text { reaction of ROO } \cdot\left[(\mathrm{moll})^{-1} \mathrm{~s}^{-1}\right] \\
& f \quad=\text { overall efficiency } \\
& I_{\mathrm{s}} \quad=\text { chemiluminescence intensity }
\end{aligned}
$$

in steady state condition

$C_{0} \quad=$ initial $\mathrm{ROO} \cdot$ concentration

[cps]

$$
\begin{array}{llr} 
& & {\left[\mathrm{moll}^{-1}\right]} \\
\sqrt{k_{\mathrm{b}} / f} & =\text { CL decay rate } \quad\left[\mathrm{cps}^{-1 / 2} \mathrm{~s}^{-1}\right] \\
T_{2} & ={ }^{1} \mathrm{H} \text { spin-spin relaxation time }[\mu \mathrm{s}] \\
\Delta E_{\mathrm{b}} & =\text { activation energy of } k_{\mathrm{b}} & {[\mathrm{J} \mathrm{mol}} \\
\Delta E_{\mathrm{i}} & =\text { activation energy of } R_{\mathrm{i}} & {\left[\mathrm{J} \mathrm{mol}^{-1}\right]}
\end{array}
$$

Acknowledgments. The authors thank Sumitomo Chemical Co., Ltd. for permission to publish this paper.

\section{REFERENCES AND NOTES}

1. G. E. Ashby, J. Polym. Sci., L, 99 (1961).

2. M. P. Schard and C. A. Russell, J. Appl. Polym. Sci., 8, 985 (1964).

3. G. A. George, "Developments in Polymer Degradation 3," N. Grassie, Ed., Applied Science Pub., 1981, Chapter 3, p. 173 and references in this review.

4. T. Naito, Nihon Gomu Kyoukaishi, 55, 40 (1981).

5. S. S. Stivara, J. Kimura, and L. Reich, "Degradation and stabilization of Polymers," Vol. 1, H. H. G. Jellinek, Ed., Elsevier, Amsterdam, 1982, Chapter 1, p. 1 and references in this review.

6. E. Niki, PETROTECH., 9, 583 (1986).

7. Z. Osawa, Bousakanri, 33, 1 (1989).

8. G. A. George, Polym. Deg. Stab., 1, 217 (1979).

9. G. A. George, G. T. Eggelstone, and S. Z. Riddell, J. Appl. Sci., 27, 3999 (1982).

10. G. A. George, G. T. Egglestone, and S. Z. Riddell, Polym. Eng. Sci., 23, 412 (1983).

11. A. H. Eakaeod and E. N. Yynka, Khim. Drev., 46 (1985).

12. Z. Osawa, S. Wu, and F. Konoma, Polym. Deg. Stab., 22, 97 (1988).

13. S. K. Brauman and J. G. Pronko, J. Polym. Soc., Polym. Phys. Ed., 26, 1205 (1988).

14. L. Audouin-Jirackova and J. Verdu, J. Polym. Sci., Polym. Chem. Ed., 25, 1205 (1987).

15. L. Zlatkevich, Polym. Eng. Sci., 24, 1421 (1984).

16. L. Zlatkevich, J. Polym. Sci., Polym. Phys. Ed., 23, 1691 (1985).

17. L. Zlatkevich, Polym. Deg. Stab., 19, 51 (1987).

18. L. Reich and S. S. Stivara, "Autooxidation of Hydrocarbons and Polyolefins," Marcel Dekker, Inc., New York, N.Y., 1969.

19. Gear Oven Life is the time taken to generate crack on the surface of specimen under heating at $150^{\circ} \mathrm{C}$. It was determined according to JIS K7212. 